\title{
Human Factors in the Design of Wheelchair Tray Tables: User Research in the Co-Design Process
}

\author{
Abdullah Alshangiti ${ }^{1,2}$, Mohammad Alhudaithi ${ }^{1,2}$, Abdullah Alghamdi ${ }^{1}$ \\ ${ }^{1}$ Human-Computer Interaction (HCI) Design Lab, Riyadh, Saudi Arabia \\ ${ }^{2}$ King Abdullah University for Science and Technology (KAUST), Thawal, Saudi Arabia \\ abdullah.alshangitiekaust.edu.sa
}

\begin{abstract}
Wheelchair tray tables offer a convenient way for wheelchair users to carry out daily tasks such as eating, reading, and using mobile devices. However, most tray tables are made to serve the majority of wheelchair users and are inaccessible to some with a limited range of motion. In our work, we address this issue by exploring the ergonomic problems and possible solutions. In this paper, we describe the human factors in the design and development of powered wheelchair tray tables. The process of humanistic co-design relies on the direct involvement of the targeted demographic in the design process. This ensures the outcome is centered around the specific needs of the individual. Our approach employs user research studies (e.g., interviews, questionnaires, and actively working with a wheelchair using co-designer) as a means towards gleaning valuable insight into the needs of wheelchair users. In these studies, we sought to explore their experiences with using tables made for wheelchairs. We also collected data about whether the tray tables required external assistance to stow and use, and the problems they faced using existing solutions. We then highlighted the various specific needs presented by the codesigners and questionnaire respondents. These needs are embodied into scenario-based personas in which they may find themselves in need of a table for use with their wheelchairs. Deriving these personas from our survey results provides an effective method of keeping the insight gathered present throughout the design process. Implications for design are discussed.
\end{abstract}

\section{$1 \quad$ Introduction}

Individuals with spinal cord injuries, arthritis, balance disorders, and other conditions or diseases are typical users of wheelchairs. Research is underway to advance wheelchair design to prevent fatigue, reduce dependencies on caregivers or accommodate improved comfort related to stable surfaces for placing items while improving safety, functional performance and accessibility to the community of wheelchair users [1]. Wheelchair tables are designed with the majority of users in mind. However, some wheelchair-using individuals find their specific needs unfulfilled by what is currently available [2].

Human factors is defined as the science concerned with the application of what we know about people, their abilities, characteristics, and limitations to the design of equipment they use, environments in which they function, and jobs they perform [3]. Our approach is a human-centered and interdisciplinary co-design process that aims to innovate on and address complex challenges facing persons with disabilities (PwDs). It involves the use of scenarios and personas to highlight the human factors in the design process. Scenario-based personas are used in user-centered design to cater to the specific needs and frustrations of the end-user [4,5]. In our case, the main purpose of using personas is to provide a way to display the information gathered from the user research segment of our project in a useful way for the design process. Our 
approach consists of a text description of the user and situation as well as a visual illustration of the user and location. These provide a description of the predicted behaviors and desires of the end-users and allow us to effectively cater to their desires and frustrations, which will ensure their comfort.

The remainder of this paper is structured as follows: Section 2 presents an overview of background and literature in the scope of user-centered design for wheelchairs. Section 3 describes the user research methods that we used, and results are presented in Section 4. We conclude in Section 5 with a summary of human factors in the design of wheelchair tray tables and an overview of directions for future research.

\section{Background Information}

\section{$2.1 \quad$ Uses of Personas}

Personas can take the form of a photo of a person and a text description. There are also instances where they take the form of a silhouette superimposed onto a stock photo of the persona's location and a brief text description [5]. These representations could also be printed on tangible models, as shown in Fig. 1.

Previous research into the use of scenario-based personas as a means for presenting user analysis studies has established their use within the humanistic co-design community $[5,6]$. Personas can be used to present user information that may otherwise be misinterpreted if presented as statistical figures. The use of fictitious personas in the design process is outlined within the work of Aquino et al. where they are used as a user modelling tool to simplify communication and aid in project decision making [6].

\subsection{The Development of Wheelchair Designs}

Power wheelchairs are used to increase the physical capabilities of a person with disabilities. However, certain commercial products do not completely address the needs of their user base, such as navigating narrow passages and servicing their broken wheelchairs [2]. Participatory design for the production of power wheelchairs has been used to provide comprehensive input in conjunction with subject matter experts such as doctors and accessibility researchers [2].

\section{Materials and Methods}

Wheelchair trays are specially designed platforms or surfaces that attach to wheelchairs, providing a firm table for eating, working, reading, and other activities. In the process of requirements gathering, we sought to understand the ergonomics of existing wheelchair trays, and the challenges users encounter in their use of such devices. In this study, existing co-design methods and design principles were aligned with the Humanistic Co-Design model for assistive technology and tailored through a Design Innovation (DI) process to develop solutions with co-designers (i.e. Users of wheelchairs). Specifically, this study involved exploratory studies with co-designers and requirements elicitation from the community of wheelchair users through surveys. These studies were within the Design Innovation framework that is built, in part, on the UK Council's ‘4D’ (Discover, Define, Develop, Deliver) model of design [7]. 

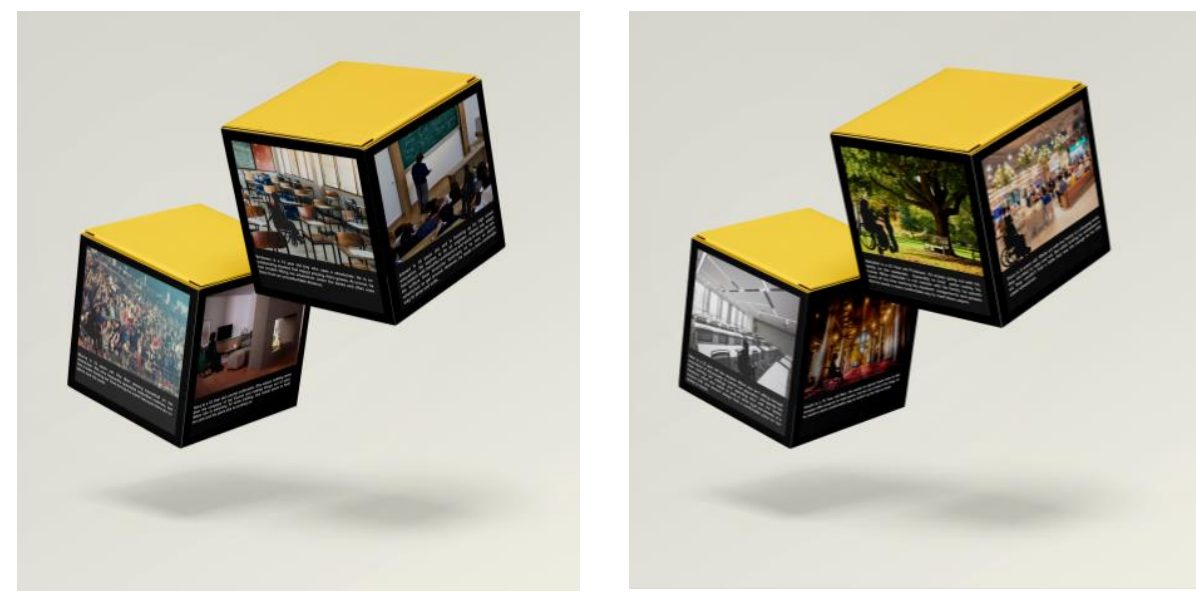

Fig. 1. Tangible scenario-based personas for wheelchair users in different use cases with tray tables; taking into account user preferences, socio-cultural factors and contexts of use.

An online questionnaire was distributed to communities of PwDs via our co-designer, to gather data for our personas. The survey yielded 10 responses in a timeframe of 2 weeks. Basic demographic information about our respondents like age, gender, and place of residence was gathered. Following that, participants were asked about information relating to their experience with wheelchairs and wheelchair tray tables, and the problems they faced using them. The respondents were asked about their main uses for wheelchair tables and the heaviest items they place on them. We also conducted an interview with our co-designer, a wheelchair user. This gave us more insight into how specifically he used wheelchair tables. It also allowed us to deepen our understanding of the specific frustrations that wheelchair users face while using different tray table solutions. We were also able to develop a user journey map from his insights and comments. Using the responses gathered as a basis for the use cases, we constructed our personas in the form of a piece of text describing fictional characters aligned with PwDs in our target user population and outlining the contexts of use [3]. Above the text is a silhouette in the image of the individual placed on a photo of a scene to describe the context of use. Fig. 1

\section{$4 \quad$ Results and Discussion}

Understanding relationships between people, objects and their environments is important when considering human factors in designing assistive and accessible technologies. There is limited information on the difficulties PwDs experience in mounting objects on wheelchair tray tables and maneuvering their wheelchairs during daily activities. Insights from our user research studies were distilled into design implications for the shape, form, and function of mounting tray tables to wheelchair frames.

After sending out the questionnaire to various online wheelchair user communities, we received responses about different problems they faced while using current wheelchair tray tables. The main aim of the survey was gathering useful qualitative data, including a significant portion of what is in Table 1. The demographic information was as follows: $10 \%$ of our respondents were female, and $90 \%$ were male. $10 \%$ were under 15 years of age, $70 \%$ were between 15 and 35 years old, and $20 \%$ were above the age of 35 . 


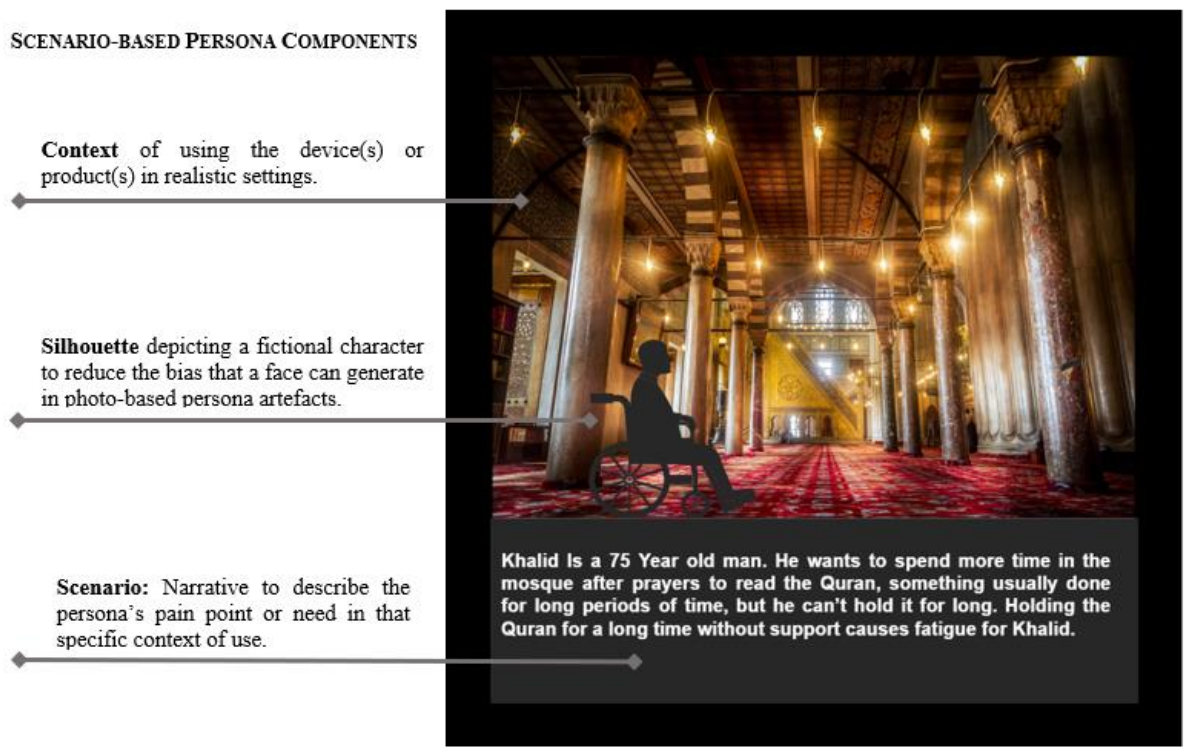

Fig. 2. Scenario-based Persona comprised of a brief text outlining a design consideration and a relevant illustration to communicate the setting of the situation.

The main takeaway from our results were the key features our respondents outlined. For example, one answered that the heaviest item they wish to place on a tray table would be a large Qur'an (approximate weight $3 \mathrm{Kg}$ ), so one of the personas we designed had this as a primary use case as depicted in Fig. 2.

Respondents also described their main uses for such a table which influenced our design considerations in Table 1. The human factors in the design of wheelchair tray tables are listed in the left column of Table 1, and the corresponding design considerations for tray tables are described in columns 2 and 3. Findings from the abovementioned user studies shed light on usability and accessibility issues as well as layout design limitations in wheelchair tray tables.

The use of human factors to characterize the design considerations provides the reasoning and justification behind the design options [8-10]. It provides a factual basis to prioritize certain aspects of the user experience over others. For example, the ability to angle the table may be omitted if it interferes with the design of the folding mechanism and if the need for a folding table exceeds that of an angled one from the perspective of the user. It ultimately provides a way to relate the issues the users face to the potential solutions, as noted in $[11,12]$. In future work, the factors will all be evaluated when developing and implementing the final design of the table 
Table 1. Human Factors in the Design of Wheelchair Tray Tables

\begin{tabular}{|c|c|c|}
\hline \multirow{2}{*}{ Human Factors } & \multicolumn{2}{|l|}{ Design Considerations } \\
\hline & $\begin{array}{l}\text { Shape, Form, or } \\
\text { Function }\end{array}$ & $\begin{array}{l}\text { Tray Table } \\
\text { Feature(s) }\end{array}$ \\
\hline $\begin{array}{l}\text { Vision: Maneuvering } \\
\text { Visibility }\end{array}$ & $\begin{array}{l}\text { Transparency for } \\
\text { visibility }\end{array}$ & Polycarbonate Tray \\
\hline $\begin{array}{l}\text { Vision: Control } \\
\text { Visibility }\end{array}$ & $\begin{array}{l}\text { Salient visibility for } \\
\text { components and } \\
\text { ergonomic design for } \\
\text { the controls }\end{array}$ & $\begin{array}{l}\text { Controlled by a } \\
\text { button near the other } \\
\text { wheelchair controls }\end{array}$ \\
\hline $\begin{array}{l}\text { Physical Factor: Lack of } \\
\text { Dexterity }\end{array}$ & $\begin{array}{l}\text { Electrically folding } \\
\text { without large } \\
\text { movements from the } \\
\text { user. }\end{array}$ & Folding feature \\
\hline $\begin{array}{l}\text { Physical Factor: Muscle } \\
\text { Fatigue }\end{array}$ & $\begin{array}{l}\text { The ability to hold books and } \\
\text { tablets at an angle that is } \\
\text { comfortable to the user. }\end{array}$ & Angled table \\
\hline $\begin{array}{l}\text { Motivational Factor: Not } \\
\text { being burdensome as not to } \\
\text { disincentivize use. }\end{array}$ & Activated by a button. & Flip Tray \\
\hline $\begin{array}{l}\text { Physical factor: Keeping } \\
\text { cups stable during use. }\end{array}$ & $\begin{array}{l}\text { Depression within the surface } \\
\text { to prevent cups from sliding }\end{array}$ & Cup Holder \\
\hline $\begin{array}{l}\text { Social factor: not relying on } \\
\text { caregivers. }\end{array}$ & $\begin{array}{l}\text { Independent folding without } \\
\text { caregiver's assistance }\end{array}$ & Folding feature \\
\hline $\begin{array}{l}\text { Physical Factor: Facilitating } \\
\text { easy maintenance and } \\
\text { cleaning }\end{array}$ & $\begin{array}{l}\text { Locks for tray table } \\
\text { mounting }\end{array}$ & $\begin{array}{l}\text { Unlockable mounting } \\
\text { clamps }\end{array}$ \\
\hline $\begin{array}{l}\text { Physical Factor: keeping } \\
\text { items from falling off }\end{array}$ & $\begin{array}{l}\text { Rough table surface to } \\
\text { prevent items from sliding }\end{array}$ & Rough table surface \\
\hline
\end{tabular}

\section{Conclusion}

In this study, we were able to establish an initial connection between the users requirements and the physical design by utilizing scenario-based personas. We also gained a wealth of information from our co-designer through an initial interview and further correspondence. Going forward, we plan on conducting semi-structured interviews with a selected sample from our survey respondents to gain a deeper insight into their day to day needs regarding the use of tray tables and peripherals mounted on wheelchairs.

This study furthers our understanding of the difficulties and pain points that wheelchair-using PwDs experience during daily activities that might be alleviated by the ergonomic design of wheelchairs' tray tables. This knowledge will assist clinicians, technologists and researchers in two areas: in choosing design features that are ecologically valid for wheelchair users; and, in identifying areas for further development specific to the use of tray tables for wheelchairs. 


\section{Acknowledgement}

We thank the Humanistic Co-Design Initiative and the Human-Computer Interaction (HCI) Lab for supporting this work. We also thank the Saudi Authority for Intellectual Property (SAIP) and the Saudi Health Council's National Lab for Emerging Health Technologies for hosting and mentoring this work. We also thank Mawaddah AlSabban for her graphics in the design of scenario-based personas. The authors would also like to acknowledge the contribution of Ali Alnasser who was key during the initial stages of the co-design process, and the mentorship of Dr. Mark Oleksak and Dr. Ragad Allwihan. This work is part of the authors' project that is carried out under the CoCreate Fellowship for Humanistic Co-Design of Access Technologies.

\section{References}

1. Cooper, RA and Boninger, ML and Spaeth, DM and Ding, D and Guo, S and Koontz, AM and Fitzgerald, SG and Cooper, R and Kelleher, A and Collins, DM (2006) Engineering better wheelchairs to enhance community participation. IEEE Transactions on Neural Systems and Rehabilitation Engineering, 14 (4). 438 - 455. ISSN 1534-4320

2. Isabella Gomez Torres, Gaurav Parmar, Samarth Aggarwal, Nathaniel Mansur, and Alec Guthrie. 2019. Affordable Smart Wheelchair. In Extended Abstracts of the 2019 CHI Conference on Human Factors in Computing Systems (CHI EA '19). Association for Computing Machinery, New York, NY, USA, Paper SRC07, 1-6. DOI:https://doi.org/10.1145/3290607.3308463

3. Wickens, C. D., Gordon, S. E., \& Liu, Y. 2004. An introduction to human factors engineering. Upper Saddle River, N.J., Pearson Prentice Hall.

4. Christiane Moser, Verena Fuchsberger, Katja Neureiter, Wolfgang Sellner, and Manfred Tscheligi. 2012. Revisiting personas: the making-of for special user groups. In CHI '12 Extended Abstracts on Human Factors in Computing Systems (CHI EA '12). Association for Computing Machinery, New York, NY, USA, 453-468. DOI:https://doi.org/10.1145/2212776.2212822

5. Alicia Valls Saez and Muriel Garreta Garreta Domingo. 2011. Scenario-based persona: introducing personas through their main contexts. In CHI '11 Extended Abstracts on Human Factors in Computing Systems (CHI EA '11). Association for Computing Machinery, New York, NY, USA, 505. DOI:https://doi.org/10.1145/1979742.1979563

6. Plinio Thomaz Aquino Junior and Lucia Vilela Leite Filgueiras. 2005. User modeling with personas. In Proceedings of the 2005 Latin American conference on Human-computer interaction (CLIHC '05). Association for Computing Machinery, New York, NY, USA, 277-282. DOI:https://doi.org/10.1145/1111360.1111388

7. "Design Innovation Learning Modules - What Is Design Innovation?" Dimodules, www.dimodules.com/whatisdi.

8. Paciello, M.G., 1996. Designing for people with disabilities. interactions, 3(1), pp.15-16.

9. Bennett, C.L. and Rosner, D.K., 2019, May. The Promise of Empathy: Design, Disability, and Knowing the" Other". In Proceedings of the 2019 CHI Conference on Human Factors in Computing Systems (pp. 1-13).

10. Van der Woude, L.H., Veeger, D.J.E. and Rozendal, R.H., 1989. Ergonomics of wheelchair design: a prerequisite for optimum wheeling conditions. Adapted Physical Activity Quarterly, 6(2), pp.109-132.

11. Rajapakse, R., Brereton, M., Sitbon, L. and Roe, P., 2015, December. A Collaborative approach to design individualized technologies with people with a disability. In Proceedings of the Annual Meeting of the Australian Special Interest Group for Computer Human Interaction (pp. 29-33).

12. De Couvreur, L. and Goossens, R., 2011. Design for (every) one: co-creation as a bridge between universal design and rehabilitation engineering. CoDesign, 7(2), pp.107-121. 